\section{High Coxiella burnetii Seroconversion Rate in Veterinary Students, the Netherlands, 2006-2010}

\author{
Marit M.A. de Lange, Wim van der Hoek, \\ Peter M. Schneeberger, Arno Swart, Dick J.J. Heederik, \\ Barbara Schimmer, Inge M. Wouters
}

Author affiliations: National Institute for Public Health and the Environment, Bilthoven, the Netherlands (M.M.A. de Lange, W. van der Hoek, A. Swart, B. Schimmer); Jeroen Bosch Hospital, 's-Hertogenbosch, the Netherlands (P.M. Schneeberger); Utrecht University, Utrecht, the Netherlands (D.J.J. Heederik, I.M. Wouters)

DOI: https://doi.org/10.3201/eid2612.200063

We examined Coxiella burnetii seroconversion rates by measuring $C$. burnetii IgG among 2 cohorts of veterinary students. During follow-up of 118 seronegative veterinary students, 23 students seroconverted. Although the clinical importance of the presence of antibodies is unknown, veterinary students should be informed about the potential risks for $Q$ fever.

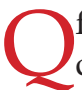
fever is caused by the bacteria Coxiella burnetii and can manifest as acute or chronic illness. Veterinarians who care for livestock are prone to C. burnetii infection (1,2). A high seroprevalence among veterinary students has been reported (3-5). However, the incidence of $\mathrm{Q}$ fever and associated risk factors during veterinary training are still unknown. We conducted a longitudinal study at the Faculty of Veterinary Medicine of Utrecht University (FVMUU), Utrecht, the Netherlands, in which we followed incoming, seronegative veterinary students and investigated potential associated factors for seroconversion.
Veterinary students who started in 2006 or 2008 at FVMUU were invited to participate. After obtaining written informed consent, we collected blood samples, and participants completed a baseline questionnaire. From participants who began at FVMUU in 2006 (cohort 2006), $\leq 2$ additional blood samples and follow-up questionnaires were obtained in 2008 and 2010. Students who started in 2008 (cohort 2008) provided 1 follow-up blood sample and 1 follow-up questionnaire in 2010.

Serum samples were tested for IgG against phase I and II of C. burnetii, using an indirect immunofluorescence assay as previously described (3). Those samples with IgG phase I or II IgG $\geq 1: 32$ were classified as C. burnetii seropositive. Seroconversion was defined as the change observed in a participant who was IgG seronegative at baseline and seropositive in a follow-up sample.

We determined differences in demographics and past animal exposure between seropositive and seronegative participants at baseline. Risk factors for seroconversion were estimated by using univariable logistic regression analyses through generalized estimating equations models (Appendix, https://wwwnc.cdc. gov/EID/article/26/12/20-0063-App1.pdf).

At the beginning of their veterinary training, 447 students were invited to participate in the study. Of those, 131 participated, of whom $13(10 \%)$ were C. burnetii IgG seropositive at baseline. Students who were seropositive at baseline were more likely to have lived on a farm and to have had contact with cattle and poultry (Appendix Table 1).

Of the 118 participants seronegative at baseline, 78 started their training in 2006 and 40 in 2008 (Figure). Of those students, 23 seroconverted during the follow-up period of 362 person-years, translating to an incidence of 0.06 / person-year. Of the 17 seroconversions in cohort 2006, 11 occurred between baseline and the

\begin{tabular}{|c|c|c|c|}
\hline & 2006 & 2008 & 2010 \\
\hline No. in 2006 cohort & 78 & 77 & 73 \\
\hline $\begin{array}{l}\text { Questionnaire no., \% } \\
\text { Blood no., \% }\end{array}$ & $\begin{array}{l}77 / 78(99) \\
78 / 78(100)\end{array}$ & $\begin{array}{l}77 / 77(100) \\
72 / 77(94)\end{array}$ & $\begin{array}{l}71 / 73(97) \\
63 / 73(86)\end{array}$ \\
\hline Seropositive no., \% & $0 / 78(0)$ & $11 / 77(15)$ & $17 / 63(27)$ \\
\hline No. in 2008 cohort & & 40 & 40 \\
\hline $\begin{array}{l}\text { Questionnaire no., \% } \\
\text { Blood no., \% }\end{array}$ & & $\begin{array}{c}39 / 40(98) \\
40 / 40(100)\end{array}$ & $\begin{array}{c}38 / 40(95) \\
40 / 40(100)\end{array}$ \\
\hline Seropositive no., \% & & $0 / 40 /(0)$ & $6 / 40(15)$ \\
\hline
\end{tabular}

Figure. Follow-up timeline illustrating number and percentages of seronegative participants at baseline, per follow-up moment, in study of Coxiella burnetii seroconversion rate in veterinary students, the Netherlands, 20062010. The 17 seropositive students in 2010 include the 11 students who already seroconverted during 2006-2008 and were censored from risk factor analysis in 2010. 
Table. Characteristics from follow-up questionnaire in association with Coxiella burnetii seroconversion among 118 veterinary students seronegative at baseline, the Netherlands*

\section{Characteristic}

Age group, $y$

\begin{tabular}{c}
$\leq 20$ \\
21 \\
$\geq 22$ \\
\hline Sex \\
M \\
F
\end{tabular}

Regular exposure to cigarette smoke Yes

No

Living on a farm with cattle

Yes

No

Living on a farm with sheep or goats

Yes

No

Living on a farm with pigs

Yes

No

Living on a farm with chickens

Yes

No

Regular contact with cattle outside veterinary training

Yes

No

Regular contact with goats outside veterinary training

Yes

No

Regular contact with horses outside veterinary training

Yes

No

Regular contact with pigs outside veterinary training

Yes

No

Regular contact with chickens outside veterinary training

Yes

No

Regular contact with sheep outside veterinary training Yes

No

History of performing animal nursing on farm where they lived Yes

No

History of working with straw or hay on farm where they lived

Yes

$$
\text { No }
$$

History of working with fertilizers on farm where they lived Yes

No

History of performing plant nursing on farm where they lived Yes

No

No. years after study start $†$

2

4

Cohort‡

2006

2008

Chosen specialization during veterinary training

Individually kept animals

Veterinary public health or farm animals

${ }^{*} \mathrm{ND}$, not determined because of low numbers.

†Only adjusted for cohort.

†Only adjusted for number of years after the study.
Odds ratio $(95 \% \mathrm{Cl})$ $p$ value

Referent

$0.9(0.2-3.5)$

$1.3(0.4-4.2)$

0.85

0.69

Referent

$0.7(0.2-2.3)$

$1.1(0.4-2.8)$

0.81

Referent

ND

ND

$6.2(1.4-28.1)$

Referent

0.02

ND

ND

$3.0(0.3-35.0)$

0.39

Referent

0.3 (0.1-2.7)

Referent

0.31

$0.6(0.1-3.8)$

0.56

Referent

0.7 (0.3-1.7)

0.40

Referent

ND

ND

$0.5(0.1-3.8)$

0.50

Referent

4.4 (1.2-16.7)

0.03

Referent

$3.6(0.9-14.3)$

0.07

Referent

$6.4(1.6-26.1)$

Referent

3.2 (0.5-19.6)

Referent

3.1 (0.3-33.5)

Referent

Referent

$1.0(0.3-2.9)$

Referent

$0.7(0.3-2.0)$

Referent

$1.6(0.5-5.0)$ 
first follow-up, and 4 occurred between the first and second follow-up (Appendix Table 2). None of the seroconverted participants reported a diagnosis of acute $Q$ fever from a general practitioner or medical specialist, suggesting all cases were mild or asymptomatic. In addition, no participants had serologic indication of a chronic infection. Of the 20 investigated characteristics, "living on a sheep or goat farm," "having contact with sheep outside [veterinary] training," and "working with hay, straw, silage grass, or animal feed" outside FVMUU increased the odds of seroconversion (Table).

We were not able to identify education-related potential risk factors, such as courses taken, for 2 reasons. First, the curriculum changed during our study, so participants from the 2006 and 2008 cohorts took different courses, causing low power in the analysis. Second, within each cohort, little variation occurred in courses taken. Another limitation of this study is our assumption of a constant risk for C. burnetii exposure during the study period. Students seem to have been at higher risk for infection in the first 2 study years, although we cannot draw definite conclusions from this small group of students.

Identified risk factors for seroconversion were not education-related. Proximity to (aborting) small ruminants, such as goats and sheep, was a risk factor in an outbreak in the Netherlands (6). Veterinary students have a high prevalence of animal contacts outside their education (7). In addition, contact with hay, straw, silage grass, or animal feed, is a known risk factor for human $Q$ fever (8). A major outbreak of acute $Q$ fever occurred in the Netherlands during 2007-2010 (9), and some students might have contracted the infection then, although increased seroprevalence of $Q$ fever in veterinary students before that outbreak has been reported (3).

In conclusion, we found a considerable C. burnetii seroconversion rate among veterinary students. Although the clinical importance of the presence of antibodies is unknown, students should be advised at the beginning of their education about potential risks and instructed to seek care if they experience symptoms of acute or chronic $Q$ fever infection.

\section{Acknowledgments}

We would like to express our gratitude to all participants of the study. Many thanks to coworkers at the Institute for Risk Assessment Sciences involved in recruitment of the participants and serum sample collection (Lot Bannink, Manon Bogaerts, Isabella van Schothorst, Esmeralda Krop, Siegfried de Wind, Jack Spithoven, Marieke Oldenwening, Lidwien Smit, Haitske Gravenland, and Bernadette Aalders). We would like to thank the laboratory technicians in the Serology Unit of the Department of Medical Microbiology and Infection Control at Jeroen Bosch Hospital for their work in analyzing serum samples. We would also like to thank Roel Coutinho of the Julius Center University Medical Center Utrecht for reviewing the manuscript.

\section{About the Author}

Dr. de Lange is an epidemiologist at the National Institute for Public Health and the Environment. She conducted her $\mathrm{PhD}$ research on $\mathrm{Q}$ fever. Her other research interests include respiratory infections, such as influenza and respiratory syncytial virus.

\section{References}

1. Van den Brom R, Schimmer B, Schneeberger PM, Swart WA, van der Hoek W, Vellema P. Seroepidemiological survey for Coxiella burnetii antibodies and associated risk factors in Dutch livestock veterinarians. PLoS One. 2013;8:e54021. https:/ / doi.org/10.1371/journal.pone.0054021

2. Dal Pozzo F, Martinelle L, Léonard P, Renaville B, Renaville R, Thys C, et al. Q fever serological survey and associated risk factors in veterinarians, Southern Belgium, 2013. Transbound Emerg Dis. 2017;64:959-66. https://doi.org/ 10.1111 /tbed.12465

3. de Rooij MM, Schimmer B, Versteeg B, Schneeberger P, Berends BR, Heederik D, et al. Risk factors of Coxiella burnetii ( $Q$ fever) seropositivity in veterinary medicine students. PLoS One. 2012;7:e32108. https:/ / doi.org/10.1371/journal. pone.0032108

4. Meadows SL, Jones-Bitton A, McEwen SA, Jansen J, Patel SN, Filejski C, et al. Prevalence and risk factors for Coxiella burnetii seropositivity in small ruminant veterinarians and veterinary students in Ontario, Canada. Can Vet J. 2017;58:397-9.

5. Valencia MC, Rodriguez CO, Puñet OG, de Blas Giral I. Q fever seroprevalence and associated risk factors among students from the Veterinary School of Zaragoza, Spain. Eur J Epidemiol. 2000;16:469-76. https://doi.org/10.1023/A:1007605414042

6. Roest HI, Tilburg JJ, van der Hoek W, Vellema P, van Zijderveld FG, Klaassen $\mathrm{CH}$, et al. The $\mathrm{Q}$ fever epidemic in the Netherlands: history, onset, response and reflection. Epidemiol Infect. 2011;139:1-12. https:/ / doi.org/10.1017/ S0950268810002268

7. Samadi S, Spithoven J, Jamshidifard AR, Berends BR, Lipman L, Heederik DJ, et al. Allergy among veterinary medicine students in the Netherlands. Occup Environ Med. 2012;69:48-55. https://doi.org/10.1136/oem.2010.064089

8. Rustscheff S, Norlander L, Macellaro A, Sjöstedt A, Vene S, Carlsson M. A case of $Q$ fever acquired in Sweden and isolation of the probable etiological agent, Coxiella burnetii from an indigenous source. Scand J Infect Dis. 2000;32:605-7. https:// doi.org/10.1080/003655400459496

9. van der Hoek W, Morroy G, Renders NH, Wever PC, Hermans MH, Leenders AC, et al. Epidemic $Q$ fever in humans in the Netherlands. Adv Exp Med Biol. 2012; 984:329-64. https://doi.org/10.1007/978-94-007-4315-1_17

Address for Correspondence: Marit M.A. de Lange, National Institute for Public Health and the Environment, Centre for Infectious Disease Control Netherlands, Antonie van Leeuwenhoeklaan 9, 3721 MA, Bilthoven, the Netherlands; email: marit.de.lange@rivm.nl 